v. 5 , no. 1

ISSN: $1983-3873$

\title{
MECANISMOS DE (NÃO) EQUIVALÊNCIA EM FRASEOLOGIAS DA LÍNGUA TEWE E DO PORTUGUÊS
}

\author{
STRATEGIES OF EQUIVALENCE OR NOT EQUIVALENCE \\ OF PHRASEOLOGY OF TEWE LANGUAGE AND PORTUGUESE
}

\author{
Zacarias Alberto Sozinho Quiraque \\ Maria Helena de Paula \\ Universidade Federal de Goiás
}

\begin{abstract}
RESUMO: Neste artigo, pretende se apresentar primeiras considerações sobre mecanismos de equivalência (ou não equivalência) em fraseologias, a partir de uma descrição morfológica e semântica das fraseologias da língua Tewe (língua bantu falada em Moçambique, província de Manica, cidade de Chimoio, com o código S.13b na classificação de Guthrie, 1967-71) e da língua portuguesa (língua românica originada do galécio-português inicialmente falado no Reino da Galiza e no norte de Portugal e hoje falado em quarto continentes). Para atingir este objetivo, nossa proposta se baseou no método que consiste na recolha e análise de obras que abordam sobre o conceito e a importância do estudo das fraseologias. Além da metodologia acima citada, será usado o método introspectivo, pois serão aplicados conhecimentos de um dos autores deste trabalho sobre a sua língua materna, a língua Tewe, e aplicados conhecimentos de ambos os autores para a língua portuguesa. Através da descrição das fraseologias nas duas línguas, pretende se mostrar que não há equivalência morfológica das fraseologias, mas apenas uma equivalência semântica, na perspectiva de inter-relação entre língua e cultura.
\end{abstract}

PALAVRAS-CHAVES: Fraseologias; Equivalência; Língua Tewe; Língua Portuguesa.

ABSTRACT: This paper aims to introduce first considerations about equivalence mechanisms (or no equivalent) in phraseology, beginning with a morphological and semantics description of the phraseology of Tewe language (a Bantu language spoke in Mozambique, Manica, Chimoio, with code S.13b in Guthrie classification, 1967-71) and Portuguese (one Romance language originated from Galecio Portuguese, initially spoken in the Kingdom of Galicia and northern Portugal and today spoken in four continents). To achieve this goal, our proposal was based on the method that consists in the collection and analysis of old works that approach on the concept and importance of the study of phraseology. In addition to the above-mentioned methodology, we use the introspective method because we use the knowledge of one of the authors of this work on their mother tongue, the language Tewe, and applied knowledge of both authors into Portuguese. By describing the phraseology in both languages, it aims to show that there is no morphological equivalence of phraseology, but only a semantic equivalence, where we the perspective of inter-relationship between language and culture.

KEYWORDS: Phraseology, Equivalence, Tewe Language, Portuguese. 


\section{Revista do SELL}

v. 5 , no. 1

ISSN: $1983-3873$

\section{Introdução}

O estudo das Fraseologias constitui área de interesse para muitos estudiosos como Xatara (1998), Lopes (2004), Tullio (2005) e Langa (2007) a título de exemplos. O presente trabalho realiza-se no âmbito de um estudo que visa analisar e compreender o uso de diferentes fraseologias que fazem parte da vida quotidiana das comunidades (rurais e urbanas). Para desenvolver este trabalho, optou-se por analisar o contexto do uso das fraseologias da cultura Tewe e da cultura brasileira, neste último caso, em contexto rural situado no interior do Brasil, especialmente no estado de Goiás.

Pretendemos com este trabalho apresentar primeiras considerações sobre mecanismos de equivalência (ou não equivalência) em fraseologias a partir de uma descrição morfológica e semântica das fraseologias da língua Tewe.

A perspectiva morfológica e semântica que será adotada neste trabalho pretende embasar-se nas lições de que a composição mórfica pode conduzir a aspectos de sentidos da palavra ou lexia. No nível morfológico, é nosso propósito descrever a estrutura morfológica das fraseologias que serão objeto de estudo deste trabalho, tendo em conta que as duas línguas apresentam estruturas completamente diferentes, pois uma (a língua moçambicana Tewe) é aglutinante e a outra (o português) é flexional. No nível semântico, procuraremos, no português, uma fraseologia que contém o mesmo significado que na língua Tewe, tendo em conta as diferentes culturas representadas nas duas fraseologias destas línguas, uma vez que o trabalho tem como um dos objetivos discutir a equivalência e não equivalência de tradução de fraseologias de duas línguas históricas diferentes, tomando Tewe como língua de saída e português como língua de chegada. Neste contexto, através da descrição das fraseologias nas duas línguas, pretende se mostrar que não há equivalência morfológica das fraseologias, mas apenas uma equivalência semântica que sempre ampara pela perspectiva de inter-relação entre língua e cultura. 


\section{Revista do SELL}

v. 5 , no. 1

ISSN: $1983-3873$

A motivação deste trabalho partiu da definição do próprio conceito de idiomatismos que, segundo Ntsanwisi (1985, p. 11, citado por LANGA, 2007, p. 14), "são construções peculiares de uma língua não traduzíveis, literalmente, para outra língua". Portanto, a nossa intenção é procurar entender e mostrar como e quando é que estas expressões são usadas por diferentes pessoas das duas culturas que serão analisadas neste trabalho.

\subsection{Sobre a Língua Tewe}

Nos últimos decênios do século dezanove, o método histórico-comparativo deu passos para a descoberta de relações entre o Sânscrito e as línguas europeias (grego, latim, persa, germânico). A descoberta de semelhança entre essas línguas veio evidenciar a existência de uma relação de parentesco entre elas, que tinham uma origem comum e constituíam uma família indo-europeia. Nesta linha de ideias, o método histórico comparativo usado para comparar línguas indo-europeias também viria a ser aplicado ao estudo das línguas africanas, exemplo das línguas bantu (faladas na África subsaariana), em especial uma delas, a língua Tewe.

Moçambique é um país multilíngue e multicultural. Estas características devemse ao facto de ser um país onde se falam várias línguas que servem a várias culturas. Destas línguas, um número superior a 20 são chamadas de línguas Bantu, que além de serem usadas na comunicação diária, constituem as línguas maternas e mais utilizadas na condução da vida do dia-a-dia da maior parte da população moçambicana. A Língua Tewe é uma língua bantu falada em Moçambique, na província de Manica, em particular na cidade de Chimoio, nos distritos de Gondola e Makhate e nos postos administrativos de Matsinho e Ingomai (EDUARDO, 1999).

Segundo Werner (1919), citado por Ngunga (2014, p. 29),

foi Bleek (1851) quem, depois de ter chamado pronominal prefix language (línguas de prefixo pronominal) às línguas da África subsahariana que comparou e observou a existência de um sistema comum de concordância por meio de prefixos, utilizou pela primeira vez o termo Bantu para referir a estas línguas. 


\section{Revista do SELL}

v. 5 , no. 1

ISSN: $1983-3873$

Bleek (1851) usou o método comparativo para mostrar que havia uma relação genética entre diversas línguas da África subsaariana (ALMEIDA, 2012, citado por NGUNGA, 2014). Estudando as línguas de África, ele descobriu algumas caraterísticas comuns (morfológicas e genéticas) entre muitas línguas faladas desde a África Central até a África do Sul pelo que, mais tarde, as designou de bantu.

Muitos investigadores deram continuidade ao estudo destas línguas, tanto que um trabalho desenvolvido por Meinhof (1899), através do método diacrônico, permitiuIhe concluir que as línguas bantu deviam ter origem numa língua que chamou de Protobantu comum. Ele chamou de Proto-Bantu a essa língua ancestral ${ }^{1}$ hipoteticamente reconstituída com base nos dados fonéticos recolhidos de algumas línguas atualmente conhecidas (NGUNGA, 2014).

De acordo com Chimbutane (1991, p. 41, com destaques do autor),

O Proto-bantu teria sido falado na região dos grandes lagos, donde, segundo a história, os "bantu/bantos" se dispersaram em direção ao sul do continente. Segundo este autor, [Malcon Guthrie], "ba-" seria, no "proto-bantu", o morfema do plural próprio da classe que pertence o nome "ntu" que significa "pessoa". Então "bantu" significaria "pessoas". Assim Guthrie chamou a estas línguas com caraterísticas comuns e tem mais ou menos a mesma palavra para designar "pessoas" de línguas "bantu", isto é, traduzido literalmente línguas de "pessoas".

Observemos os seguintes exemplos que designam o termo "pessoas" ou "gente" em algumas línguas bantu moçambicanas:

$\begin{array}{lll}\text { Makhuwa: } & \text { a-nthu } & \text { 'pessoas ou gente', } \\ \text { Tewe: } & \text { a-nhu } & \text { 'pessoas ou gente' } \\ \text { Changana: } & \text { va-nhu } & \text { 'pessoas ou gente' } \\ \text { Nyanja: } & \text { wa-nhu } & \text { 'pessoas ou gente', } \\ \text { Yao: } & \text { vaa-ndu } & \text { 'pessoas ou gente', } \\ \text { Gitonga: } & \text { ba-thu } & \text { 'pessoas ou gente' }\end{array}$

${ }^{1}$ Proto-Bantu seria a língua-mãe que teria dado origem a restantes línguas semelhantes. 


\section{Revista do SELL}

v. 5 , no. 1

ISSN: $1983-3873$

Observando os exemplos acima, constatamos que os morfemas a-, va-, wa,vaa-, e ba- são alomorfes do prefixo do pro-bantu ba- que indica o plural deste nome, e os morfemas -nthu, -nhu, -ndu, -thu seriam a variação, nestas línguas, do tema nominal -ntu do proto-bantu.

Na classificação de Guthrie (1967-71)2 a língua Tewe ${ }^{3}$ pertence ao grupo Shona (S.10), tendo como código de classificação S.13b. Portanto, o código atribuído a esta língua, na classificação de Guthrie, assumia que ela pertence à Zona S, Grupo Shona S.10, língua Manyika S.13, e Tewe como dialeto com código S.13b.

Embora reconheçamos a existência de estudos e discussão que se têm vindo a fazer sobre a diferença entre língua e dialeto desde Antiguidade ${ }^{4}$ até aos nossos dias, não será nosso objetivo discutir a diferença entre estes dois termos e que para nosso estudo usaremos o termo língua para designar esta variante do grupo de línguas que Bleek (1851) chamou de bantu. Em Moçambique, esta questão é controvérsia até nos dia de hoje desde a implantação, por razões políticas e ideológicas, do português como única língua oficial e a tentativa atual de se valorizar e padronizar as mais de vinte (20) línguas nacionais daquele país. Portanto, ao longo deste trabalho iremos considerar Tewe como uma língua, tal como é tratada não só pelos seus falantes, mas também por vários estudos sobre as Línguas Bantu de Moçambique.

Dados do censo populacional de 2007 de Moçambique, extraídos do INE (2010) por Ngunga e Faquir (2011), dizem que 15.670.424 de moçambicanos de 5 ou mais

\footnotetext{
${ }^{2}$ Autor e investigador, nascido na Inglaterra aos 10 de Fevereiro de 1903 e morreu aos 22 de Novembro de 1972. Foi um dos pioneiros nos estudos sobre as Línguas que Bleek (1851) designou de Bantu.

${ }^{3} \mathrm{Na}$ sua classificação, Guthrie (1967-71), chamou esta língua de tebe. Presumimos que era assim que esta era chamada, pois na ortografia padronizada daquela língua, o grafema b representa o som implosivo bilabial vozeado [b], porque nas línguas do grupo shona este som ocorre com mais frequência quando comparado ao som oclusivo bilabial vozeada [b], que nesta língua é representado pelo grafema bh.

${ }^{4}$ Segundo Leroy (1967), Dante foi um homem do período medieval que se interessou de modo original pelos problemas da linguagem e da relação entre os dialetos. No seu livro De vulgari eloquentia, escrito em 1303, Dante distinguiu com uma exatidão notável, quatorze formas de dialetos italianos. Olhando na nossa época atual, estudos há que se debruçam sobre questões de língua/dialeto, ou seja, o que exatamente diferencia uma língua de um dialeto. Estes estudos tornam se mais falaciosos quando se chega na fase de padronização de uma língua, quando os linguistas deparam com diferentes dificuldades em traçar critérios para se definir uma língua como padrão e as outras como variantes dentro do mesmo grupo linguístico.
} 


\section{Revista do SELL}

v. 5 , no. 1

ISSN: $1983-3873$

anos de idade, distribuídos nas 11 províncias de país, são falantes de cada uma das 23 línguas. Dentre estes, $87.15 \%$ falam as línguas Bantu; $10.8 \%$ falam o português como língua materna; $2.0 \%$ falam outras línguas que não são especificadas nos dados do INE; $0.05 \%$ falam línguas de sinais. Do número da população falante de uma língua apresentado acima, estimam-se em 259.790 o número de falantes da língua Tewe, "considerando-se os cinco anos de idade como a idade mínima tomada pelo INE como referência para se considerar um ser humano como falante de uma língua [...]" (NGUNGA e BAVO, 2011, p. 15).

\subsection{Sobre a língua Portuguesa}

A língua portuguesa é uma língua românica originada do galego-português, à época falado no Reino da Galiza e no norte de Portugal. É a quinta língua mais falada no mundo, a terceira mais falada no hemisfério ocidental e a mais falada no hemisfério sul da Terra. Dados do Instituto Superior de Ciências do Trabalho e da Empresa (ISCTE/IUL), publicados na página do Instituto de Camões, indicam a existência de 254,54 milhões de "falantes nativos" de português, correspondente à população dos oito (8) países de língua oficial portuguesa ${ }^{5}$, nomeadamente Angola, Brasil, Cabo Verde, Moçambique, Portugal, Timor Leste, São Tomé e Príncipe, Guiné Bissau, sendo o Brasil o país com maior número de falantes (cerca de 200 milhões de falantes). 0 português também é conhecido como a língua de Camões, em homenagem a uma das mais conhecidas figuras literárias de Portugal, Luís Vaz de Camões, autor de Os Lusíadas.

Reconhecendo os diferentes tipos de variedades do português distribuído em três círculos (Interior, Exterior e de Expansão) referenciados por Lopes (2004), para o nosso trabalho iremos usar como referência os provérbios do Português de Brasil (PB), que faz parte do Círculo Interior. Salienta-se que na ótica deste autor, a variedade do português falado em Moçambique faz parte do Círculo Exterior, o português dos cinco

5 Disponível em: http://www.instituto-camoes.pt/comunicados-imprensa/dia-da-lingua-portuguesa-e-dacultura-na-cplp-5-de-maio\#sthash.y2Owhahm.dpuf. Acesso em 22 abr. 2015 


\section{Revista do SELL}

v. 5 , no. 1

ISSN: $1983-3873$

estados africanos chamados de expressão portuguesa, variedades que emergem através do processo de nativização em contextos plurilíngues, sendo a tendência atual a de busca e possível desenvolvimento de uma norma em nível interno de cada um dos países (LOPES, 2004).

\section{Metodologia}

Para materializar o presente trabalho e atingir os objetivos acima preconizados, o mesmo baseou-se nas seguintes metodologias: Na parte teórica, usou-se o método de revisão bibliográfica, que consiste na recolha e análise de obras que debruçam sobre o conceito a e importância das expressões idiomáticas em diferentes línguas. Utilizamos, também, o método de entrevista e introspetivo, com o uso de um rádio gravador, um bloco de nota e uma esferográfica para apontar as expressões que nos foram facultadas por diferentes falantes da língua Tewe, residentes na cidade de Maputo há mais de dois anos, além do conhecimento de um dos autores do trabalho como falante nativo da língua Tewe. Para este tipo de estudo, segundo Xatara, Riva e Rios (2001, p. 184), "é necessário uma ampla pesquisa que envolva não apenas obras lexicográficas, mas também informantes nativos, conhecedores de sua língua materna". Os dados referentes à língua portuguesa brasileira, na variante já explicitada, buscamos no dicionário Houaiss da Língua Portuguesa, em versão electrónica (2009) e no nosso conhecimento como falantes nativos desta língua, e um dos autores deste trabalho é falante nativa do português em uso regional no sudeste do estado de Goiás.

\section{Organização do estudo}

O trabalho é composto por quatro (4) fraseologias ou expressões idiomáticas, recolhidas com diferentes informantes, falantes e praticantes nativos das duas culturas, sem especificar idade, nível de escolaridade, entre outros aspectos. Na primeira parte, 


\section{Revista do SELL}

v. 5 , no. 1

ISSN: $1983-3873$

encontramos a introdução, onde aparece uma breve contextualização do trabalho, seguida dos objetivos, metodologia usada para o seu desenvolvimento.

A segunda parte diz respeito ao seu desenvolvimento, onde apresentamos a revisão bibliográfica para uma contextualização do conceito de fraseologias e/ou expressões idiomáticas e, de seguida, a apresentação do processamento das fraseologias da cultura Tewe e da cultura no interior do Brasil. A terceira e última parte do trabalho diz respeito à conclusão em que, resumidamente, aparecem os aspectos e conceitos importantes a reter no que concerne às expressões idiomáticas em tela.

\section{Revisão bibliográfica}

Pelo fato de estarmos trabalhando com um tema polêmico e que dificilmente é consenso entre teóricos que a ele se dedicam (fraseologias ou expressões idiomáticas), antes de tudo, faz-se necessário explicitar este conceito norteador que é de extrema importância por nos manter centrados em nosso objetivo inicial. As fraseologias vêm, desde muito, sendo um dos objetos de estudo de vários linguistas que investigam a disciplina da lexicografia e estão empenhados no estudo de léxico de usos e a sua (in)traduzibilidade para diferentes línguas e culturas.

\subsection{Fraseologias e/ou Expressões Idiomáticas}

O estudo das fraseologias e dicionários fraseológicos remota desde muito tempo, até mesmo antes do Cours de Linguistique Générale (Curso de Linguística Geral) do linguista Ferdinand de Saussure, 1916. Segundo Xatara (1998, p. 14),

teoricamente Saussure foi o primeiro a chamar atenção para a existência de combinações não livres (Saussure, 1969), mas as particularidades dessas combinações foram desenvolvidas sobretudo por Bally (1951), ao instituir fraseologias como uma disciplina dentro da lexicologia. 


\section{Revista do SELL}

v. 5 , no. 1

ISSN: $1983-3873$

A autora acima acrescenta que os linguistas ocidentais (dentre eles destacam se, como pioneiros, os alemães Thun e Hausermann e o norte americano Weinrich), foram os principais seguidores de Bally, quanto ao aprofundamento dos aspectos teóricos dessa questão, são os russos como Vinoghradov (ETTINGER, 1982, e TRISTÁ, 1988, citados por XATARA, 1998). Portanto, o estudo das fraseologias não constitui assunto de hoje, tanto que já vem sendo objeto de estudo no período antes da Linguística se instituir área científica.

Segundo Silva (2014, p. 25), "tendo se firmado como disciplina científica no início do século $\mathrm{XX}$, a fraseologia, apesar de ser relativamente nova, já conta com várias vertentes que teorizam cada uma, sobre a delimitação de seu objeto de estudo".

A discussão sobre se fraseologias são ou não expressões idiomáticas e se os provérbios fazem parte das fraseologias e/ou expressões idiomáticos ou ainda se fazem parte de outra área de estudo chamada paremiologia vem desde há muito. Para citar alguns exemplos, segundo Silva (2014), os fraseologismos são denominados de várias maneiras, de acordo com a abordagem adotada: locuções fraseológicas, fraseolexemas, frasemas, idiomatismos, lexemas idiomáticos, expressões idiomáticas, lexias complexas, dentre outras. Para acrescentar a esta lista, Corpas Pastor (1996) citato por Alvez (2014) aponta certa homogeneidade quanto ao emprego do termo fraseologia para designar o estudo do que ele chama de combinações léxicas e o problema em delimitar o seu objeto de estudo. Na lista de Silva (2014), Corpas Pastor (1996) apresenta termos como frases feitas, locução, expressão pluriverbal, unidades fraseológicas; Biderman (2001) prefere o termo idiotismo, enquanto que Davel (s/d) prefere usar o termo expressões cristalizadas; e ainda há outros que usam léxico de usos, unidades fraseológicas etc. como termos para designar as fraseologias.

Na perspectiva de Xatara (1998), esta submacroárea (fraseologia) vai dividir-se em fraseologias populares (como os idiomatismos, as gírias, os provérbios e afins) e em fraseologias técnico-científicos (em que se encontram as expressões terminológicas). O que podemos analisar dos autores acima é que enquanto Corpas Pastor (1996) e Silva (2014) consideram o termo fraseologia(s) e expressão idiomática como termos que designam o mesmo objeto, mas com diferentes terminologias, Xatara 


\section{Revista do SELL}

v. 5 , no. 1

ISSN: $1983-3873$

(1998) considera fraseologia como um termo de uma ciência macro dentro do qual encontramos as expressões idiomáticas, as gírias, os provérbios (que são objeto de estudo deste trabalho) e outras expressões.

Para efeitos deste estudo, usaremos a terminologia fraseologias e/ou expressões idiomáticas, conforme Xatara (1998). As expressões idiomáticas fazem parte de muitos e outros tipos de léxicos de usos, frequentes no dia-a-dia de diferentes comunidades no mundo. "O léxico de uma língua é o repositório da cultura e da história de um povo que o (re)cria e dele faz uso e que está ativo nas práticas linguísticas cotidianas desses falantes, servindo-Ihes a nomear e categorizar as múltiplas práticas de cultura" (SIQUEIRA, 2013, p. 5).

Segundo Cunha (1997), citado por Tullio (2005, p. 299), "na origem etimológica da palavra idiomático, idio significa elemento de composição derivado de grego idio-, de ídios, isto é, próprio, pessoal, privativo". O mesmo autor acrescenta que apesar de bastante usado em trabalhos sobre música, o termo idiomático não se encontra neles profundamente discutido. Por outro lado, outras áreas o fazem com mais frequência, como a literatura, onde o termo está ligado às expressões e figuras de estilo, que deixam claras em uma primeira leitura as características básicas de um estilo poético ou um determinado autor.

$\mathrm{Na}$ Linguística, Xatara (1998) define expressão idiomática como uma lexia complexa indecomponível, conotativa e cristalizada em um idioma pela tradição cultural (XATARA, RIVA e RIOS, 2001). Para Xatara, Riva e Rios (loc. cit, p. 184.),

para identificarmos uma expressão idiomática consideramos as seguintes características: a indecomponibilidade da unidade fraseológica (quase não existindo possibilidade de substituição por associações paradigmáticas), a conotação (sua interpretação semântica não pode ser feita com base nos significados individuais de seus elementos) e a cristalização (consagração de um significado estável)

Ao tomarmos a definição de que "Idiomatismos são construções peculiares de uma língua não traduzíveis, literalmente, para outra língua" (NTSANWISI, 1985, p. xi, citado por Langa, 2007, p. 14), nosso interesse em entender como a língua Tewe 


\section{Revista do SELL}

v. 5 , no. 1

ISSN: $1983-3873$

reflete ou não possíveis movimentos da cultura brasileira em terras moçambicanas, em que pese as peculiaridades culturais impressas nas expressões em estudo, se nos colocou imperativo na tentativa de entender os lastros da lusofonia e os seus impactos, ou não, nas diversas dinâmicas que envolveram a colonização portuguesa, intercontinentalmente. Esta definição nos deixou intrigados em buscar contestar ou comprovar a tese aí posta: de fato, é impossível a tradução das expressões idiomáticas da língua de uma língua para outra, notadamente da língua Tewe para o português, em variante rural usada no interior do Brasil?

Outro autor que procura fazer um estudo dos idiomatismos é Lopes (2004, p. 68), para quem "Idiomatismos são expressões que funcionam como unidades singulares e cujo significado não é possível deduzir das suas partes em separados". Pelo nosso entender, este ponto de vista não foge muito da ideia de Ntsanwisi (1985).

$\mathrm{Na}$ óptica de Nhaombe (2006), expressões idiomáticas estão correlacionadas com os significados pragmáticos culturalmente institucionalizados e ao uso social apropriado da língua no contexto. Se olharmos para esta definição, principalmente no que se refere ao uso dos idiomatismos no seu contexto, devemos prestar muita atenção na tradução de uma expressão. Esta atenção deve incidir nas estratégias culturais ligadas, não só às competências linguísticas e comunicativas das duas línguas, mas, também ao conhecimento e experiências da cultura da comunidade falante de ambas as línguas.

O conteúdo de discurso das expressões idiomáticas fez e faz parte das culturas humanas desde há muito tempo. Eles são a expressão do conhecimento e da experiência do povo que se traduzem em poucas palavras, de maneira rimada e ritmada, muitas vezes com alegria e bom humor para revelar mitos, crenças coletivas, concepções, costumes, comparações e similitudes, constituindo assim uma parte importante de cada cultura.

Elas têm o dom de incidir sobre aquele núcleo permanente da realidade do Homem, e daí decorre sua verdadeira realidade. Para além de terem como objetivo, a manifestação da verdadeira sabedoria das culturas, tradições e realidades vividas numa comunidade, os idiomatismos expressam também críticas pesadas, conselhos, 


\section{Revista do SELL}

v. 5 , no. 1

ISSN: $1983-3873$

ironias contra o egoísmo, avareza, inveja, generosidade, sinceridade, grandeza, factos e toda sorte de formação moral em todas as culturas.

Segundo Davel (s/d, p. 2), "no caso das Expressões Idiomáticas, a equivalência constitui-se o procedimento mais adequado em que os recursos podem dar conta do confronto entre duas línguas por meio de recursos estilísticos e estruturas totalmente diferentes". Esta autora acrescenta que, para muitos investigadores como Vinay e Darbelnet (1977), Vázquez-Ayora (1977) e Newmark (1988), citados por Barbosa (1990), a equivalência é a substituição de um segmento de texto da Língua Original (LO) por um outro segmento da Língua Traduzida (LT) que não o traduz literalmente, mas que é equivalente funcionalmente.

\subsection{Processamento das Fraseologias e/ou Expressões Idiomáticas}

Como referimos antes, as fraseologias ou expressões idiomáticas que serão analisadas neste trabalho foram fruto de uma entrevista a falantes nativos da cultura tewe. Como organização das expressões, primeiro aparece a fraseologia na cultura Tewe, seguida da sua descrição morfológica (sobre a legenda das abreviaturas da descrição morfológica ver no final do texto). Depois aparece a expressão equivalente no português da cultura brasileira, também seguida da sua descrição morfológica. Por

fim, apresentaremos o sentido e o ensinamento que as duas expressões trazem em ambas as línguas. Por não se tratar de um trabalho de investigação muito amplo, a parte que diz respeito a tradução literal das fraseologias da língua Tewe para língua portuguesa não será incluído no processamento destas expressões, pois importa-nos aqui somente fazer uma análise morfológica e o processamento semântico das expressões nas duas culturas em estudo.

\subsubsection{Descrição da estrutura morfológica das expressões idiomáticas nas línguas Tewe e portuguesa em busca de equivalência de sentidos.}




\section{Revista do SELL}

v. 5 , no. 1

ISSN: $1983-3873$

De acordo com Nhaombe (2002, p. 4-5), citado por Langa (2007, p. 14),

ao buscar-se os equivalentes idiomáticos [...] torna-se necessário ter em atenção as estratégias linguísticas e culturais, ligadas ao conhecimento e experiência coletiva da comunidade e as de natureza estrutural da sua organização linguística interna.

É no encalço desta afirmação que apresentamos a análise das estruturas morfológicas das fraseologias que serão o objecto de estudo no nosso texto nas duas línguas.

1.

Expressão na língua Tewe: Descrição Morfológica:

Equivalente em Português: Descrição Morfológica:

\section{Ku-shata ko-mu-nhu ku-ri mu-moyo}

PV15-feíce / PC15.-PN1sg.-pessoa / PC15-estar / PLI18- coração

\section{Quem vê cara não vê coração}

Pro.Indef. / Verb.(3ํㅡ. p., sg.) / Sub. / Adv.Neg. / Verb. (3ª p., sg.) / Sub.

\section{Sentido e Ensinamento}

Nas duas línguas, as duas expressões, expressam a ideia de que não é pelas aparências que se julga a bondade/bondosidade ou a maldade de uma pessoa, ou de uma coisa, pois a verdade está dentro do seu coração. Este expressão idiomática aconselha que não julguemos as pessoas pelas aparências mais pelo seu coração ou seus atos de cada dia, pois a aparência da pessoa não nos diz nada. Quando interpretada na cultura Tewe, é que existem homens que se vestem bem na rua, mas são ladrões. Existem também, mulheres com beleza exterior, mas não têm sentimentos amorosos. Por isso não apreciemos os homens e nem as mulheres pela parte exterior e primeiro devemos olhar para os seus corações (sentimentos) para as julgar. Não confiemos facilmente nos nossos amigos sem que saibamos o que de facto eles pensam de nós.

\section{2.}




\section{Revista do SELL}

v. 5 , no. 1

ISSN: $1983-3873$

Expressão na língua Tewe:

Descrição Morfológica:

Equivalente em Português:

Descrição Morfológica:
Gunwe rimwe a-ri-cwhany-i inda

Dedo / Num. / MNeg.-PC5-matar-MNeg. / Piolho

\section{A união faz a força.}

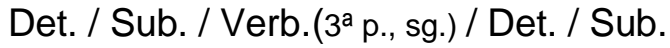

\section{Sentido e Ensinamento}

Estas fraseologias parecem evidentes, pois sublinham a potencialização do todo pela interação das partes. Elas estão associadas ao processo no qual se conseguem maiores/melhores resultados através da cooperação entre as pessoas. Uma pessoa sozinha faz nada, é necessário que tenha ajuda dos outros para trabalharem em comum, de modo a desenvolverem o país, o mundo, a comunidade o bairro, a escola, etc. O ensinamento é de que devemos ter o espírito de nos ajudar um aos outros.

\section{3.}

Expressão na língua Tewe: Ci-no u-mambo ci-no ma-gum-o

Descrição Morfológica: PN7-ter/MT / PN14-chefe / PC7-ter/MT / PDer--chegar-SDer.

Equivalente em Português e Descrição Morfológica:

Não há bem que sempre dure, nem mal que nunca se acabe.

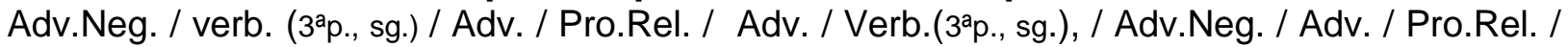
Adv.Neg. / Obj.Ind. / verb.(3âp., sg.)

\section{Sentido e Ensinamento}

Na vida em sociedade, não podemos pensar que tudo o que possuímos é eterno, mas saber que tudo tem um início e terá um fim, pois até a própria vida humana tem o seu fim na terra. Tudo o que nasce morrerá, portanto, não devemos "gingar" para os outros, pois amanhã podemos ser nós sem nada e também precisaremos de ajuda. Portanto, enquanto possuirmos uma riqueza, devemos conviver em solidariedade com os outros partilhando, e não os desprezando.

4.

Expressão na língua Tewe: $\quad$ Tsika ndi-tsik-ew-o 


\section{Revista do SELL}

v. 5 , no. 1

ISSN: $1983-3873$

Descrição Morfológica: $\quad$ Pisa! / MS-pisar-Ext.Verb.-VF

Equivalente em Português:

Ser unha e carne

Descrição Morfológica:

Verb.(inf.) / Sub. / Conj. / Sub.

\section{Sentido e Ensinamento}

Pessoas unidas por uma forte relação de amizade; pessoas inseparáveis; amigos íntimos, pessoas que estão sempre juntos. Amizade muito forte.

\section{Considerações finais}

Importa recordar que este trabalho tem como um dos objetivos fazer uma descrição morfológica e semântica das fraseologias da língua Tewe e da língua portuguesa falada no Brasil com o intuito de mostrar que não há equivalência morfológica das fraseologias, mas apenas uma equivalência semântica, pois, no nível morfológico, as duas línguas apresentam estruturas completamente diferentes. A língua moçambicana Tewe é aglutinante e a maioria das palavras é formada pela união de morfemas e o português é flexional, com tendência acentuada a recorrer à flexão e com diferentes funções marcadas pelos diferentes morfemas. Neste contexto, vimos também que os critérios usados para descrição morfológica de ambas as fraseologias são completamente diferentes, pois as duas línguas apresentam estudo morfológico diferente.

Consequentemente, não há equivalência morfológica das fraseologias, mas apenas uma equivalência semântica; na perspectiva da inter-relação entre língua e cultura, procuramos identificar, no português, uma fraseologia que contivesse o mesmo significado que a da língua Tewe, considerando as diferentes culturas representadas nas fraseologias aqui apresentadas.

Estas expressões não se traduzem, se considerarmos a morfologia de ambas as línguas, porque são unidades congeladas, com discurso repetido, usadas habitualmente para executar atos comunicacionais, e se tornarem formas socialmente convencionadas para a execução desses mesmos atos naquela própria língua. Assim, como expressões idiomáticas 


\section{Revista do SELL}

v. 5 , no. 1

ISSN: $1983-3873$

interpessoais, elas estão em correlação com os significados pragmáticos culturalmente institucionalizados das duas línguas, constituindo assim, formas convencionadas de falar, ligadas ao uso social apropriado da língua em contexto, ou seja, à competência pragmática.

\section{Referências}

ALVES, Carolina Fernandes. Inclusão e tratamento de unidades fraseológicas no Dicionário de Usos do Português do Brasil (2002). In: ZAVAGLIA, Cláudia (Org.). Domínio de Linguagem: Fraseologia e Paremiologia. v. 8, n. 2. Uberlândia-Brasil: EDUFU. p. 87-117. 2014. Disponível em: <http://www.seer.ufu.br/index.php/dominiosdelinguagem> Acesso em: 27 abr. 2015.

BIDERMAN, Maria, Tereza. C. Teoria Linguística. 2.ed. Martins Fontes. São Paulo: 2001.

CHIMBUTANA, Feliciano. Línguas Bantu ou Línguas Bantas?. Revista Tempo. MaputoMoçambique. $n$ 1083. P. 40-42. 1991. Disponível me: $<$ http://www.google.com.br/url?sa=t\&rct=j\&q=\&esrc=s\&source=web\&cd=3\&cad=rja\&uact=8\&v ed=0CCwQFjAC\&url=http\%3A\%2F\%2Fwww.catedraportugues.uem.mz\%2Flib\%2Fdocs\%2F Perguntugues \%2520Linguas bantu bantas.pdf\&ei=ikuJVY3bH4i ggTo9JKgBw\&usg=AFQj CNGBWqZMiaqGeuehCX1YWyTTpXx1Ww\&sig2=zskF1RNpWczTnl-9FiyHYw>. Acesso em: 25 fev 2013.

DAVEL, Alzira da Penha Costa. A (Im)possibilidade de Tradução das Expressões Cristalizadas. UFES, S/D. Disponível em: $<$ http://www.cchla.ufrn.br/visiget/pgs/pt/anais/Artigos/Alzira\%20da\%20Penha\%20Costa\%20D avel\%20\%20\%28UFES\%29.pdf>. Acesso em: 2 fev. 2014

EDUARDO, M. Algumas notas de tradução das línguas maternas. Cooperação Alemã. Chimoio-Gtz: Manica. 1999.

GUTHRIE, Malcolm. Comparative Bantu: an introduction to the comparative inguistics and prehistory of the Bantu languages. 4 vols. Letchworth UK \& Brookfield VT: Gregg International. 1967-71.

LANGA, Julieta Machimuassana. Esboço para uma análise da equivalência no léxico de usos. Folha de Linguística e Literatura 10, 14-17. UEM, 2007.

LANGA, Julieta Machimuassana. Estratégias de Tradução de algumas expressões referenciais da língua portuguesa para língua tsonga. 1991. LT41. Tese (Licenciatura em 


\section{Revista do SELL}

v. 5 , no. 1

ISSN: $1983-3873$

Linguística) - Faculdade de Letras, Universidade Eduardo Mondlane. Maputo, Moçambique, 1991.

SIQUEIRA, Gisele Martins. Campos Lexicais e Cultura no Caminho das Bandeiras. 2013. 183 f. Dissertação (Mestrado em Letras e Linguística) - Faculdade de Letras - Universidade Federal de Goiás, Goiânia, 2013

LOPES, Armando Jorge. A Batalha das línguas: Perspectiva sobre Linguística Aplicada em Moçambique. Impressa universitária: UEM, 2004.

NGUNGA, Armindo. Introdução à Linguística Bantu. Imprensa Universitária: 2. ed. UEM: Maputo, 2014.

; FAQUIR, Osvaldo. Padronização da Ortografia das Línguas Moçambicanas: Relatório do III Seminário. Col. "As Nossas Línguas III". CEA: Maputo, 2011.

; BAVO, Názia. Práticas Linguísticas em Moçambique: Avaliação da Vitalidade Linguística em seis Distritos. Col. "As Nossas Línguas IV". CEA: Maputo, 2011.

NHAOMBE, Henrique. Ernesto. Uso idiomático da linguagem na rádio. Folha de Linguística e Literatura 9, 5-6, 2006.

SILVA, Flávia, Santos da. As palavras e a frase: o funcionamento de fraseologismos. In: ZAVAGLIA, Cláudia (Org.). Domínio de Linguagem: Fraseologia e Paremiologia. v. 8, n. 2. EDUFU: Uberlândia-Brasil. p. 25-40. 2014. Disponível em: <http://www.seer.ufu.br/index.php/dominiosdelinguagem> Acesso em: 27 abr. 2015.

TULLIO, Eduardo Fraga. O Idiomatismo nas Composições para Percussão de Luiz D'anunciação, Ney Rosauro e Fernando lazzetta: Análise, edição e performance de obras selecionadas. Escola de Música e Artes Cênicas - Universidade Federal de Goiás, 2005. Disponível em: <http://tv.ufri.br/anppom/sessao6/eduardo tullio.pdf>. Acesso em: 17 jan. 2014.

XATARA, Cláudia Maria. A Tradução para o português de expressões idiomáticas em francês. Araraquara. 1998. 253f. Tese (Doutorado em Letras: Linguística e Língua Portuguesa) - Faculdade de Ciências e Letras, Universidade Estadual Paulista, Araraquara, 1998.

XATARA, Cláudia; RIVA, Huélinton C.; RIOS, Tatiana Helena C. As dificuldades na tradução de idiomatismos. Cadernos de Tradução, v 8, n. 2, p. 184-194. Florianópolis-UFSC, 2001. Disponível em: <https://periodicos.ufsc.br/index.php/traducao/article/view/5892/5572>. Acesso em: 20 fev. 2014. 


\section{Revista do SELL}

v. 5 , no. 1

ISSN: $1983-3873$

\section{ANEXOS}

Legenda: Língua Tewe

Ext. Verb - Extensão Verbal

MS - Marca de Sujeito

MT - Marca de Tempo

MNeg. - Marca de Negação

Num. - Numeral

P.Der. Prefixo Derivacional

PV - Prefixo Verbal

PN - Prefixo Nominal

PC - Prefixo de Concordância

PLI - Prefixo de Locativo de Interioridade

S.Der. - Sufixo Derivacional

VF - Vogal Final

Nota: Os números indicam as classes nominais em que estes nomes pertencem. $E$ as classes nominais das línguas moçambicanas variam de 1 a 19 classes.

\section{Legenda: Língua Portuguesa}

Sg. - Singular

Verb. - Verbo

Inf. - Infinitivo

Sub. - Substantivo

Conj. - Conjuntivo

Det. - Determinante

3a p. - Terceira Pessoa

Obj.Ind. - Objeto Indireto

Pro.Rel. - Pronome Relativo

Pro.Int. - Pronome Interrogativo

Adv.Neg. - Advérbio de Negação 